\title{
Application of the Cell Potential Method To Predict Phase Equilibria of Multicomponent Gas Hydrate Systems
}

\author{
Brian J. Anderson, ${ }^{\dagger}$ Martin Z. Bazant, ${ }^{\ddagger}$ Jefferson W. Tester, ${ }^{\dagger}$ and Bernhardt L. Trout ${ }^{*}, \dagger$ \\ Department of Chemical Engineering and Department of Mathematics, Massachusetts Institute of Technology, \\ 77 Massachusetts Avenue, Cambridge, Massachusetts 02139
}

Received: September 30, 2004; In Final Form: February 23, 2005

\begin{abstract}
We present the application of a mathematical method reported earlier ${ }^{1}$ by which the van der Waals-Platteeuw statistical mechanical model with the Lennard-Jones and Devonshire approximation can be posed as an integral equation with the unknown function being the intermolecular potential between the guest molecules and the host molecules. This method allows us to solve for the potential directly for hydrates for which the Langmuir constants are computed, either from experimental data or from ab initio data. Given the assumptions made in the van der Waals-Platteeuw model with the spherical-cell approximation, there are an infinite number of solutions; however, the only solution without cusps is a unique central-well solution in which the potential is at a finite minimum at the center to the cage. From this central-well solution, we have found the potential well depths and volumes of negative energy for 16 single-component hydrate systems: ethane $\left(\mathrm{C}_{2} \mathrm{H}_{6}\right)$, cyclopropane $\left(\mathrm{C}_{3} \mathrm{H}_{6}\right)$, methane $\left(\mathrm{CH}_{4}\right)$, argon $(\mathrm{Ar})$, and chlorodifluoromethane (R-22) in structure $\mathrm{I}$; and ethane $\left(\mathrm{C}_{2} \mathrm{H}_{6}\right)$, cyclopropane $\left(\mathrm{C}_{3} \mathrm{H}_{6}\right)$, propane $\left(\mathrm{C}_{3} \mathrm{H}_{8}\right)$, isobutane $\left(\mathrm{C}_{4} \mathrm{H}_{10}\right)$, methane $\left(\mathrm{CH}_{4}\right)$, argon $(\mathrm{Ar})$, trichlorofluoromethane (R-11), dichlorodifluoromethane (R-12), bromotrifluoromethane (R-13B1), chloroform $\left(\mathrm{CHCl}_{3}\right)$, and 1,1,1,2-tetrafluoroethane (R-134a) in structure II. This method and the calculated cell potentials were validated by predicting existing mixed hydrate phase equilibrium data without any fitting parameters and calculating mixture phase diagrams for methane, ethane, isobutane, and cyclopropane mixtures. Several structural transitions that have been determined experimentally as well as some structural transitions that have not been examined experimentally were also predicted. In the methane-cyclopropane hydrate system, a structural transition from structure I to structure II and back to structure I is predicted to occur outside of the known structure II range for the cyclopropane hydrate. Quintuple $\left(\mathrm{L}_{\mathrm{w}}-\mathrm{sI}-\mathrm{sII}-\mathrm{L}_{\mathrm{hc}}-\mathrm{V}\right)$ points have been predicted for the ethane-propane-water $\left(277.3 \mathrm{~K}, 12.28 \mathrm{bar}\right.$, and $\left.x_{\text {eth,waterfee }}=0.676\right)$ and ethane-isobutanewater $\left(274.7 \mathrm{~K}, 7.18 \mathrm{bar}\right.$, and $\left.x_{\text {eth,waterfree }}=0.81\right)$ systems.
\end{abstract}

\section{Introduction}

Since the first documentation nearly two centuries ago, ${ }^{2}$ natural gas clathrate-hydrates, called clathrates, have been studied for both their scientific and their technological interests. Clathrates can form plugs in natural gas transmission lines, ${ }^{3}$ and therefore, for many years, investigations have been aimed at understanding and avoiding clathrate formation. More recently, natural gas hydrates have been proposed as a relatively clean energy source. Estimates of the energy content of the methane contained in naturally occurring natural gas hydrates suggest that clathrates contain twice the energy content of all other fossil fuels in use today combined. ${ }^{4}$ However, clathrates are considered an unconventional, unproven source of fossil fuel. ${ }^{5}$ Additionally, carbon dioxide hydrates are being considered for application toward sequestration and storage of $\mathrm{CO}_{2}$.

Despite the large database of experimental clathrate phase behavior, ${ }^{6}$ the theory of clathrates is not well developed and still relies heavily on the ad hoc fitting of experimental data. The commonly used fitting procedures can usually reproduce the input data, but have poor predictive ability outside of the range of fitting. The thermodynamic reference parameters that are commonly used while fitting intermolecular potential parameters to the experimental data ${ }^{6,7}$ differ greatly from reference

* To whom all correspondence should be sent. E-mail: trout@mit.edu.

Department of Chemical Engineering.

Department of Mathematics. parameters that are determined experimentally ${ }^{8}$ or computationally. ${ }^{9}$ When these procedures are used in attempts to predict hydrate formation from gas mixtures, the intermolecular potential and reference parameters typically need adjusting ${ }^{7}$ to reproduce accurately phase equilibria and structural transitions.

Recently, we showed that the inverse temperature dependence of the Langmuir constant for natural gas hydrates contains all the necessary information to determine intermolecular potentials. ${ }^{1}$ Starting from the van der Waals and Platteeuw statistical model, ${ }^{10}$ cell potentials can be directly and unambiguously extracted from experimental equilibrium data by solving an integral equation analytically. The resulting potentials are physically meaningful and much simpler than the numerically fit Kihara potentials. Finally, given the simplicity of the spherically averaged cell potential, hydrate phase equilibria information can be calculated without the use of numerical integration techniques. When used in conjunction with reference parameters and intermolecular potentials calculated by using ab initio methods ${ }^{9}$ no fitting parameters are necessary.

This paper validates the use of the cell potential method by testing its predictive ability against experimental results, and then uses the method to make predictions that await experimental testing. In sections 2 and 3, we review the classical statistical-mechanical description of hydrates, which relates Langmuir constants to the cell potential of guest molecules. Our method is reviewed in section 4, where we obtain the cell potential from an exact solution to an integral equation. For 
comparison with other methods, in section 6 we compute cell potentials for ethane hydrates using standard fitting procedures. In section 7, we apply our method to determine cell potentials for a variety of clathrate systems. We also fit commonly used empirical intermolecular potentials to our analytical cell potentials to evaluate the validity of the former in reproducing the temperature dependence of Langmuir constants. In section 8, we test our cell potentials by predicting phase equilibria for mixed gas hydrates, including structural transitions that have not yet been observed experimentally. We summarize our results and comment on their implications in section 9.

\section{Hydrate Phase Chemical Potential Model}

A thermodynamic model corresponding to the three-dimensional generalization of ideal localized adsorption was proposed in 1959 by van der Waals and Platteeuw. ${ }^{10}$ By assuming single guest occupancy of the available water cages, neglecting variations in guest-guest interactions, and assuming negligible distortions of the empty lattice, the difference in chemical potential between clathrate and empty host lattice can then be expressed as

$$
\Delta \mu^{\beta-\mathrm{H}}=k T \sum_{i} v_{i} \ln \left(1+\sum_{J} C_{J i} \hat{f}_{J}\right)
$$

where $v_{i}$ is the number of type $i$ cavities per water molecule, $\hat{f}_{J}$ is the fugacity of guest molecule $J$ in the gas or liquid phase, which can, for example, be calculated from a mixture form of a $P V T N$ Peng-Robinson equation of state, ${ }^{11}$ and $C_{J i}$ is the Langmuir constant for a guest molecule $J$ in a cavity of type $i$ defined as

$$
\begin{aligned}
& C_{J i} \equiv \frac{Z_{J i}}{k T}=\frac{1}{8 \pi^{2} k T} \\
& \int_{V} \exp (-\Phi(r, \theta, \phi, \alpha, \beta, \gamma) / k T) r^{2} \sin \theta \mathrm{d} r \mathrm{~d} \theta \mathrm{d} \phi \mathrm{d} \alpha \mathrm{d} \beta \mathrm{d} \gamma
\end{aligned}
$$

where $Z_{J i}$ is the full configurational integral, which depends on the total interaction potential $\Phi=\sum_{i j} \Phi_{i j}$ between guest and host molecules ${ }^{12,13}$ and is, in general, a function of $r, \theta$, and $\phi$, the spherical coordinates of the guest molecule, and $\alpha, \beta$, and $\gamma$, the Euler angles that describe the orientation of the guest. To calculate the configurational integral accurately, the total interaction potential between the guest molecule and all of the host water molecules must be represented properly. In early work the potential was approximated by a two-parameter spherically symmetric Lennard-Jones potential. ${ }^{10}$ Later, a Kihara potential, with three parameters, was used to improve accuracy. However, these empirically fitted potentials are not fundamentally based on the guest-host interactions, have been shown to be aphysical, and do not match those determined using gasphase experimental data. ${ }^{6,14,15}$ Our work is based on computing physically relevant intermolecular potentials directly from $a b$ initio calculations and from single component phase data. Given intermolecular interaction potentials, the chemical phase equilibrium is calculated by methods described in our earlier work ${ }^{9,16}$ and reference state values for $\Delta \mu_{\mathrm{w}}^{0} \equiv \Delta \mu_{\mathrm{w}}^{\beta-\alpha}\left(T_{0}, 0\right), \Delta H_{\mathrm{w}}^{0} \equiv$ $\Delta H_{\mathrm{w}}^{\beta-\alpha}\left(T_{0}\right), \Delta C_{\mathrm{p}, \mathrm{w}}^{\beta-\mathrm{L}, \alpha}\left(T_{0}\right)$, and $\Delta V_{\mathrm{w}}^{\beta-\mathrm{L}, \alpha}\left(T_{0}\right)$ used are found in Table 1.

\section{Calculating the Configurational Integral}

Typically, the van der Waals and Platteeuw (vdWP) model ${ }^{10}$ is used in conjunction with the spherical-cell approximation to estimate the configurational integral. This approach is analogous
TABLE 1: Thermodynamic Reference Properties for Structure I and II Hydrates: $T_{0}=273.15 \mathrm{~K}$

\begin{tabular}{lllc}
\hline & structure I & structure II & source \\
\hline$\Delta \mu_{\mathrm{w}}^{0}(\mathrm{~J} / \mathrm{mol})^{a}$ & 1203 & 1077 & 9 \\
$\Delta H_{\mathrm{w}}^{0}(\mathrm{~J} / \mathrm{mol})$ & 1170 & 1294 & 9 \\
$\Delta V_{\mathrm{w}}^{\beta-\alpha}\left(\mathrm{m}^{3} \cdot \mathrm{mol}^{-1}\right)$ & $3.0 \times 10^{-6}$ & $3.4 \times 10^{-6}$ & 17 \\
$\Delta H_{\mathrm{w}}^{\mathrm{L}-\alpha}(\mathrm{J} / \mathrm{mol})$ & \multicolumn{2}{c}{6009.5} & \\
$\Delta V_{\mathrm{w}}^{\mathrm{L}-\alpha}\left(\mathrm{m}^{3} \cdot \mathrm{mol}^{-1}\right)$ & \multicolumn{2}{c}{$-1.598 \times 10^{-6}$} & \\
$\Delta C_{\mathrm{p}}^{\beta-\mathrm{L}}(\mathrm{J} / \mathrm{mol} \cdot \mathrm{K})$ & $-37.32+0.179\left(T-T_{0}\right)$ & 18 \\
$\Delta C_{\mathrm{p}}^{\beta-\alpha}(\mathrm{J} / \mathrm{mol} \cdot \mathrm{K})$ & $0.565+0.002\left(T-T_{0}\right)$ & 18
\end{tabular}

${ }^{a}$ Superscripts/subscripts: $\mathrm{w}=$ water; $0=$ reference state; $\beta=$ empty hydrate lattice; $\alpha=$ ice phase; $\mathrm{L}=$ liquid phase.

to the approximation made by Lennard-Jones and Devonshire in the case of liquids. ${ }^{19}$ In the spherical-cell (SC) approximation, the intermolecular potential $\Phi$ is replaced by a spherically averaged cell potential, ${ }^{10,19}$ reducing the multidimensional configurational integral in eq 2 to one dimension, thus resulting in the following relationship between the potential, $w(r)$, and the Langmuir constant,

$$
C_{J i}=\frac{4 \pi}{k T} \int_{0}^{R} \mathrm{e}^{-w(r) / k T} r^{2} \mathrm{~d} r
$$

where the cutoff distance $R$ is taken at the average radius of the cage. The exact value of $R$ is rarely significant, because at the temperatures at which clathrates form, the high-energy, repulsive portion of the integral for $r \approx R$ provides a negligible contribution. The spherically symmetric cell potential, $w(r)$, can be determined by angle averaging:

$$
w(r)=\frac{1}{4 \pi} \int_{0}^{2 \pi} \int_{0}^{\pi} \Phi_{i j}\left(r_{i j}, \theta, \phi\right) \sin \theta \mathrm{d} \theta \mathrm{d} \phi
$$

Applying eq 4 over the first coordination shell to the Kihara potential, ${ }^{20}$

$$
\begin{gathered}
\Phi_{i j}^{K}(r)=\infty \quad \text { for } \quad r \leq 2 a \\
\Phi_{i j}^{K}(r)=4 \epsilon\left[\left(\frac{\sigma-2 a}{r_{i j}-2 a}\right)^{12}-\left(\frac{\sigma-2 a}{r_{i j}-2 a}\right)^{6}\right] \quad \text { for } \quad r>2 a
\end{gathered}
$$

yields the following form for $w(r)$ :

$$
w(r)=2 z \epsilon\left[\frac{\sigma^{12}}{R^{11} r}\left(\delta_{10}+\frac{a}{R} \delta_{11}\right)-\frac{\sigma^{6}}{R^{5} r}\left(\delta_{4}+\frac{a}{R} \delta_{5}\right)\right]
$$

where

$$
\delta_{N}=\frac{1}{N}\left[\left(1-\frac{r}{R}-\frac{a}{R}\right)^{-N}-\left(1+\frac{r}{R}-\frac{a}{R}\right)^{-N}\right]
$$

and $z$ is the coordination number, $R$ again is the average cage radius, and $\sigma, \epsilon$, and $a$ are the Kihara parameters. The Kihara parameters are generally determined by numerically fitting monovariant phase equilibrium data. ${ }^{6,21}$ The resulting Kihara parameters are not unique: many different sets of $(\epsilon, \sigma$, and $a)$ values can fit the experimental data well. Furthermore, these fitted Kihara parameters do not match those obtained by fitting other experimental data, such as second virial coefficient, gas viscosity, and molecular beam scattering data. ${ }^{6}$

\section{Inversion of Langmuir Curves}

To numerically regress experimental data to preset functional forms, such as the Kihara potential, makes use of awkward and 
unnecessarily complex equations (eqs 6 and 7) and, at any rate, leads to aphysical results. Therefore, it would be preferable to find a functional form of the interatomic potential without requiring any ad hoc assumptions, a priori. Ideally, this approach should also provide accurate predictions of the properties of mixed guest systems without refitting any potential or reference parameters.

Earlier, Bazant and Trout ${ }^{1}$ described such a method by which the functional form of the intermolecular potential can be found by solving eq 3 analytically for $w(r)$. First, eq 3 is restructured as

$$
C_{J i}(\beta)=4 \pi \beta \int_{0}^{\infty} \mathrm{e}^{-\beta w(r)} r^{2} \mathrm{~d} r
$$

where $\beta=1 / k T$. The upper limit of integration is extended to $R=\infty$, which introduces negligible errors due to the low temperatures accessible in clathrate experiments.

To invert eq 8, a functional form of $C_{J i}(\beta)$ must be found. We do this by computing $C_{J_{i}}(\beta)$ from experimental data and $\mathrm{ab}$ initio data (Sections 4.1 and 4.2) and fitting the computed values of $C_{J i}(\beta)$ to a functional form (Section 4.3).

4.1. Hydrates That Occupy Only the Large Cage. To calculate Langmuir constants directly from the experimental dissociation data without ambiguity it is necessary to focus on clathrate-hydrates for which only the larger of the two sets of cavities are occupied by the guest molecules. These include ethane, cyclopropane, propane, isobutane, and certain CFC water clathrates. With single occupancy eq 1 reduces to

for structure I: $\quad \frac{\Delta \mu_{\mathrm{w}}^{\beta-\mathrm{H}}}{k T}=\frac{3}{23} \ln \left(1+C_{J, 2} \hat{f}_{J}\right)$

for structure II: $\quad \frac{\Delta \mu_{\mathrm{w}}^{\beta-\mathrm{H}}}{k T}=\frac{1}{17} \ln \left(1+C_{J, 2} \hat{f}_{J}\right)$

The "experimental" Langmuir constants can then be obtained by solving for the $C_{J i}$ values in eqs 9 and 10, and using the fact that a three-phase vapor, hydrate $(H)$, and ice $(\alpha)$ or liquid water (L) is in equilibrium at a specified temperature, $\Delta \mu_{\mathrm{w}}^{\beta-\mathrm{H}}=$ $\Delta \mu_{\mathrm{w}}^{\beta-\mathrm{L}, \alpha}$.

for structure I: $\quad C_{J 2}=\frac{\exp \left(\frac{23}{3} \Delta \mu_{\mathrm{w}}^{\beta-\mathrm{L}, \alpha} / k T\right)-1}{\hat{f}_{J}}$

for structure II: $\quad C_{J 2}=\frac{\exp \left(\frac{17}{1} \Delta \mu_{\mathrm{w}}^{\beta-\mathrm{L}, \alpha} / k T\right)-1}{\hat{f}_{J}}$

where $\hat{f}_{J}$ is calculated for the fluid phase from the $P \underline{V} T N_{i}$ mixture form of the Peng-Robinson equation of state, ${ }^{11}$ used to represent the $P V T N_{i}$ properties of the fluid phase. This equation provides a simple way to relate the "experimental" Langmuir constant of a type $J$ guest in the larger cavity to $\hat{f}_{J}$, the fugacity of guest component $J$, and $\Delta \mu_{\mathrm{w}}^{\beta-\mathrm{H}}$, the chemical potential difference between water in the hypothetical empty hydrate, and water in either an aqueous liquid phase or ice phase.

4.2. Hydrates That Occupy Both Large and Small Cages: Using Ab Initio Data. The procedure discussed above cannot be applied directly to the methane-water clathrate system or the argon-water clathrate system because methane and argon occupy both the small and the large cages in the structure I and structure II clathrates formed by the simple hydrates of methane and argon, respectively. Thus, there are two terms on the right side of eq 1, and a single set of monovariant phase data cannot be used to determine uniquely the two $C_{J i}$ values in eq 1 . Consequently, we need another method for obtaining the Langmuir constants of these systems. Using the ab initio potentials developed by Cao et al. ${ }^{22-25}$ and Anderson et al. ${ }^{9}$ is just such a method. Here, we use these to calculate the Langmuir constant at various temperatures by integrating the full 6-dimensional configurational integral over 5 hydrate shells. This method allows us to compute the Langmuir constant not only for the cages of the structure I hydrate, but also for the cages of the theoretical (unstable) structure II methane hydrate. Methane does not form a structure II hydrate as a simple (pure) hydrate ${ }^{6}$ but will form a structure II hydrate with other hydrate guests. ${ }^{6,26-29}$ Using these ab initio Langmuir constants, cell potentials were determine for methane and argon.

4.3. Functional Form of "Experimental" Langmuir Constants. Typical sets of experimental Langmuir constant data are described well by a van't Hoff temperature dependence, given by,

$$
C(\beta)=C_{0} \mathrm{e}^{m \beta}
$$

where $C_{0}$ and $m$ are specific to guest molecule $J$ and cavity $i$. This empirical van't Hoff behavior is illustrated in Figure 2 of Bazant and Trout ${ }^{1}$ and could be anticipated by using general thermodynamic considerations. ${ }^{30}$ Combining eqs 8 and 13 yields

$$
C_{0} \mathrm{e}^{m \beta}=4 \pi \beta \int_{0}^{\infty} \mathrm{e}^{-\beta w(r)} r^{2} \mathrm{~d} r
$$

a well-posed integral equation. Although there are an infinite number of solutions to the integral equation, all but one, a unique central-well solution, are aphysical, having discontinuities and/ or cusps (discontinuous derivatives) in the potential. Therefore, we selected the central-well solution to eq 14 to represent the van't Hoff temperature dependence shown in eq 13. Thus,

$$
C_{J i}(\beta)=\beta F(\beta) \mathrm{e}^{-w\left(r_{0}\right) \beta}
$$

where

$$
F(\beta)=\beta \int_{0}^{\infty} \mathrm{e}^{-\beta y} g(y) \mathrm{d} y
$$

and $g(y)$ is the inverse Laplace transform of the function

$$
G(\beta)=\frac{F(\beta)}{\beta}=\frac{C(\beta) \mathrm{e}^{\beta w_{0}}}{\beta^{2}}
$$

These lead to the general expression for the central-well potential $w(r)$ :

$$
w(r)=w_{0}+g^{-1}\left(\frac{4}{3} \pi r^{3}\right)
$$

\section{Computation of Unique, Central-Well Potentials}

In the case of perfect van't Hoff behavior, one can see that $F(\beta)=C_{0} / \beta$ and $G(\beta)=C_{0} / \beta^{2}$. The inverse Laplace transforms of these functions are $f(y)=C_{0} H(y)$ and $g(y)=C_{0} y H(y)$, respectively, where $H(y)$ is the Heaviside step function. Thus, the unique, central well potential (solution to eq 14) is:

$$
w(r)=\frac{4 \pi r^{3}}{3 C_{0}}-m \quad \text { for } \quad r \geq 0
$$


where the slope of the van't Hoff plot of the Langmuir constant is equal to the well depth $m=-w_{0}$ and the $y$-intercept $\log C_{0}$ is related to the well size measured by the volume of negative energy $m C_{0}$ with a spherical radius of

$$
r_{\mathrm{s}}=\left(\frac{3 m C_{0}}{4 \pi}\right)^{1 / 3}
$$

The cell potential may then be simplified into the following form

$$
w(r)=m\left[\left(\frac{r}{r_{\mathrm{s}}}\right)^{3}-1\right] \quad \text { for } \quad r \geq 0
$$

Equations 19-21 allow facile implementation of the cell potential method. The two unknown parameters in eq $19, C_{0}$ and $m$, can be found by first calculating the Langmuir constants for a given guest molecule in the hydrate cage over a range of temperatures. Then, one can regress $C_{0}$ and $m$ directly from the van't Hoff plot where $m=-w_{0}$.

\section{Determining Cell Potentials for One Structure Based on Known Potential Parameters for Another Structure}

Pure ethane, like methane, forms a structure I hydrate only occupying the large cages. However, when mixed with larger guest molecules, such as propane and isobutane, ethane forms a structure II hydrate. Unexpectedly, a mixture of ethane and methane, both simple structure I formers, will form a structure II hydrate. ${ }^{26-28}$ Models have been developed that characterize this structural transition, ${ }^{7,29,31}$ but the parameters used in these models were found by incorporating the mixture data and transition points in the parameter optimization process. To have models capable of predicting equilibria in systems outside the range of available experimental data, for example, for other gas mixtures or at other temperatures, unique, physically relevant ethane potential parameters are needed.

The approach that we employed to find the cell potential for ethane in a structure II is as follows. (1) Various spherically averaged intermolecular potential forms (i.e., the Kihara and various Lennard-Jones $\mathrm{L}-\mathrm{J} 6-N$ potentials) were applied and fit to the calculated cell potentials for methane in both cages of structure I. It has been stated that the repulsive interaction between the guest and host lattice is paramount; ${ }^{32,33}$ however, when calculating the Langmuir constant of a guest in a hydrate cage, the potential is effectively Boltzmann-weighted, see eq 3. Therefore, it is the volume of the attractive region, or the integration of the attractive region, that determines the Langmuir constant. Thus, we minimized a Boltzmann-weighted objective function, $\chi$, to fit the spherically averaged potentials to the calculated cell potentials.

$$
\chi=\sum_{i}^{\text {no. of radial points }}\left[\exp \left(\frac{-w_{\text {cell potential }}}{k T}\right)-\exp \left(\frac{-w_{\text {fit potential }}}{k T}\right)\right]^{2}
$$

(2) The spherically averaged potential form chosen above was fit to the ethane structure I cell potential using eq 22. (3) This fit potential was applied to ethane in a structure II lattice and the Langmuir constants were calculated. (4) From these predicted Langmuir constants, the cell potential for structure II ethane was determined. This procedure could be extended to other guests to provide a theoretical link between the cell

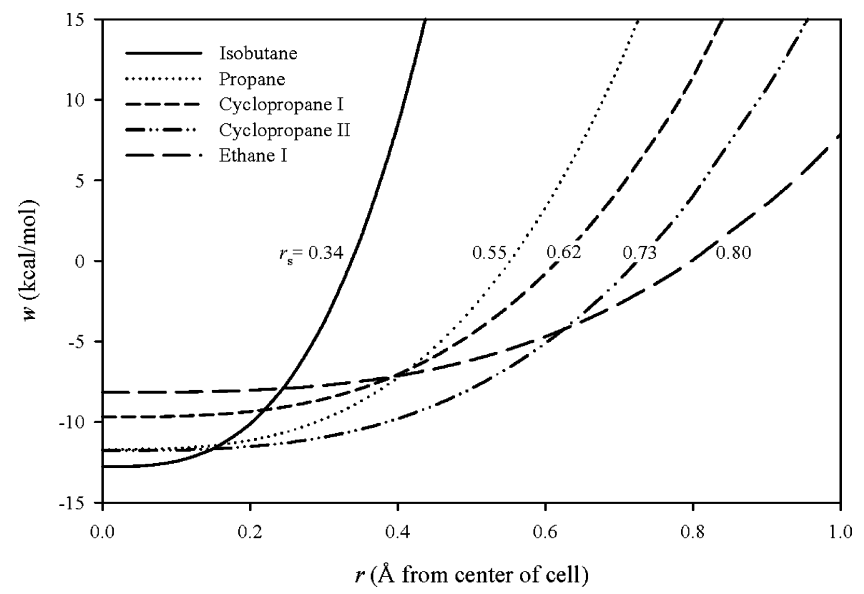

Figure 1. Cell potentials of single-cage hydrate occupying molecules calculated from pure guest experimental hydrate dissociation data.

potentials of guests in different cages, thus allowing these analytical cell potentials to be used in hydrate systems in which the guest occupies both types of cavities.

\section{Resulting Cell Potentials}

7.1. Single Occupancy Hydrates: Extracting Cell Potentials from Experimental Data. The method for extracting cell potentials for guest molecules that occupy only the large cage is discussed in Section 4.1 and the resulting potentials are shown in Figure 1. Cell potentials for all structure I and structure II guests studied are listed in Table 2 and Table 3, respectively. The reported confidence intervals are calculated by using the $95 \%$ confidence on the regression parameters, $m$ and $C_{0}$, of the van't Hoff plots (see eq 13). Although the experimental errors of the equilibrium dissociation pressures were not reported, their effect can be estimated. If the experimental error for the dissociation pressure of ethane is assumed to be a few percent, the resulting error bars on the cell potential for structure I ethane would be negligible. We expect that potential experimental error would be contained within the $95 \%$ confidence interval of the regression, $-w_{0} \pm 0.062 \mathrm{kcal} / \mathrm{mol}$ and $r_{\mathrm{s}} \pm 0.032 \AA$; therefore, the regression confidence intervals are assumed to be a good representation of the overall uncertainty.

Rodger ${ }^{58}$ suggested that temperature variations in the hydrate system could significantly alter the cavity potentials. This temperature-dependent variation in cavity potentials would manifest itself in deviations from the van't Hoff behavior. These deviations were examined by Bazant and Trout $^{1}$ and would be evident in the confidence intervals of the cell potentials listed in Tables 2 and 3. On the basis of the small confidence intervals found over a large range of temperatures (applicable to hydrate systems) the ideal van't Hoff behavior assumed in eq 13 and the subsequently derived cell potentials do indeed provide an accurate approximation of the temperature dependence of the Langmuir constants.

It should be noted that there is a strong inverse correlation between the size of the guest molecule and the resulting radius of negative energy, $r_{\mathrm{s}}$. This correlation should be expected due to the nature of hydrate-guest interactions. Using the cell potentials listed in Tables 2 and 3, we can reproduce the single component hydrate phase equilibria for the studied systems very accurately; however, this simply indicates that the form of our potential is adequate and is not a test of the overall predictive ability of the method.

The predictive ability of our cell potential method can be tested against experimental structural changes that are known 
TABLE 2: Calculated Cell Potential Parameters $w_{0}$ and $r_{\mathrm{s}}$ with $\pm 95 \%$ Confidence Intervals for Structure I Hydrates

\begin{tabular}{llrr}
\hline \multicolumn{1}{c}{ guest molecule } & temp range of & & \\
exptl data $(\mathrm{K})$ & $-w_{0}(\mathrm{kcal} / \mathrm{mol})$ & $0.803 \pm 0.032$ \\
ethane & $200-288^{34-42}$ & $8.152 \pm 0.062$ & $0.617 \pm 0.009$ \\
cyclopropane & $237-289^{43}$ & $9.677 \pm 0.022$ & $0.918 \pm 0.004$ \\
methane, small cage $\left(5^{12}\right)$ & $149-320^{a}$ & $5.645 \pm 0.007$ & $1.501 \pm 0.002$ \\
methane, large cage $\left(5^{12} 6^{2}\right)$ & $149-320^{a}$ & $5.665 \pm 0.002$ & $1.118 \pm 0.001$ \\
argon, small cage $\left(5^{12}\right)$ & $133-304^{a}$ & $4.947 \pm 0.002$ & $1.678 \pm 0.003$ \\
argon, large cage $\left(5^{12} 6^{2}\right)$ & $133-304^{a}$ & $4.463 \pm 0.002$ & $0.492 \pm 0.049$
\end{tabular}

${ }^{a}$ Cell potential calculated via ab initio potentials.

TABLE 3: Calculated Cell Potential Parameters $w_{0}$ and $r_{\mathrm{s}}$ with $\pm 95 \%$ Confidence Intervals for Structure II Hydrates

\begin{tabular}{|c|c|c|c|}
\hline guest molecule & $\begin{array}{l}\text { temp range of } \\
\text { exptl data }(\mathrm{K})\end{array}$ & $-w_{0}(\mathrm{kcal} / \mathrm{mol})$ & $r_{\mathrm{s}}(\AA)$ \\
\hline ethane & $b$ & $8.714 \pm 0.068$ & $1.474 \pm 0.066$ \\
\hline cyclopropane & $258-274^{43}$ & $11.766 \pm 0.089$ & $0.726 \pm 0.042$ \\
\hline propane & $247-278^{35,36,45-52}$ & $11.694 \pm 0.173$ & $0.552 \pm 0.062$ \\
\hline isobutane & $241-275^{49,51,53-55}$ & $12.768 \pm 0.130$ & $0.338 \pm 0.028$ \\
\hline methane, small cage $\left(5^{12}\right)$ & $149-320^{a}$ & $5.514 \pm 0.006$ & $0.911 \pm 0.004$ \\
\hline methane, large cage $\left(5^{12} 6^{4}\right)$ & $149-320^{a}$ & $4.962 \pm 0.005$ & $2.389 \pm 0.009$ \\
\hline argon, small cage $\left(5^{12}\right)$ & $133-304^{a}$ & $4.945 \pm 0.001$ & $1.106 \pm 0.001$ \\
\hline argon, large cage $\left(5^{12} 6^{4}\right)$ & $133-304^{a}$ & $3.927 \pm 0.008$ & $2.408 \pm 0.015$ \\
\hline trichlorofluoromethane (R-11) & $266-281^{44}$ & $15.973 \pm 1.122$ & $0.120 \pm 0.092$ \\
\hline dichlorodifluoromethane (R-12) & $264-285^{44,56}$ & $11.089 \pm 0.551$ & $1.308 \pm 0.467$ \\
\hline bromotrifluoromethane (R-13B1) & $266-280^{44}$ & $11.941 \pm 0.493$ & $0.589 \pm 0.189$ \\
\hline chloroform & $272-274^{57}$ & $13.105 \pm 3.375$ & $0.686 \pm 2.896$ \\
\hline $\mathrm{R}-134 \mathrm{a}$ & $275-283^{56}$ & $10.323 \pm 0.288$ & $1.794+0.328$ \\
\hline
\end{tabular}

${ }^{a}$ Cell potential calculated via ab initio potentials. ${ }^{b}$ Cell potential calculated via structure I cell potential.

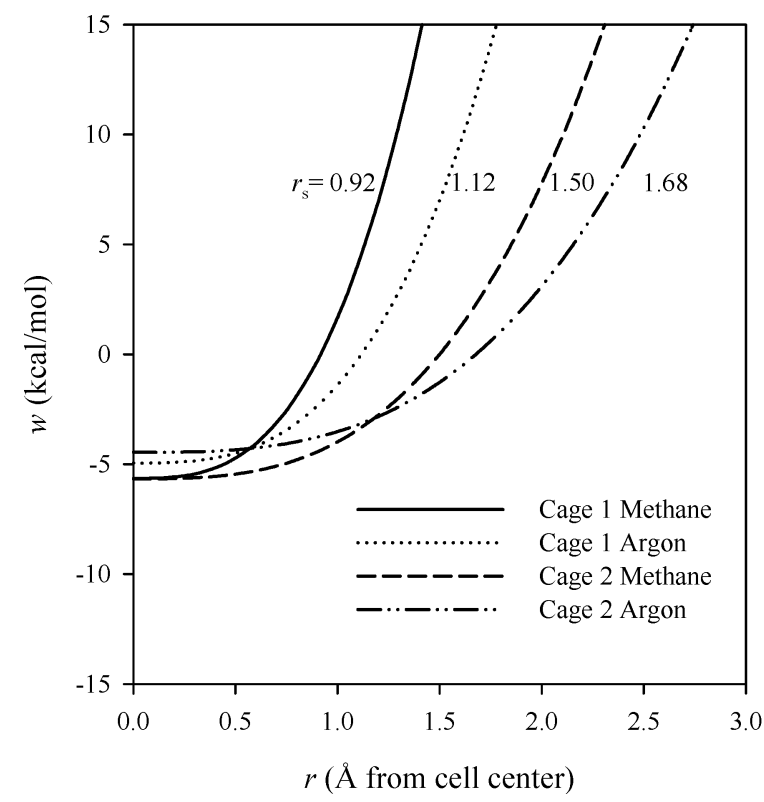

(a)

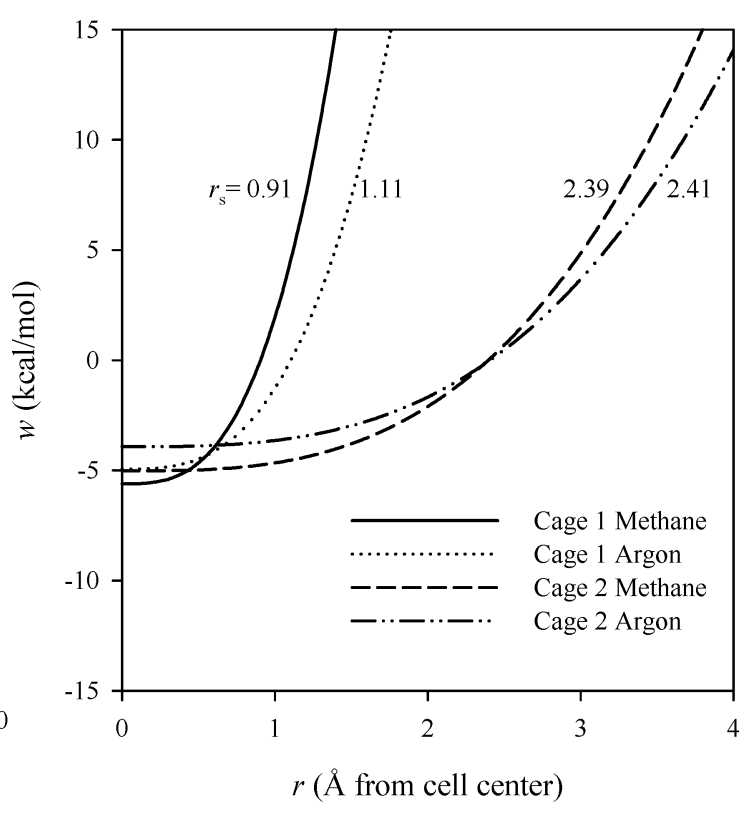

(b)

Figure 2. Cell potentials of methane and argon in structure I (a) and structure II (b) lattices. Cell potentials were calculated by using an ab initio site-site potential. ${ }^{9}$

to occur. For example, cyclopropane undergoes a structural transition as a function of temperature, ${ }^{43}$ namely that between 257.1 and $274.6 \mathrm{~K}$ cyclopropane forms a structure II hydrate, while outside that region it forms structure I. Using the cyclopropane cell potentials listed in Tables 2 and 3 we predict these transitions to occur at 256.5 and $274.6 \mathrm{~K}$, respectively.

7.2. Using Ab Initio Potentials To Determine Cell Potentials. As explained in Section 4.2, site-site ab initio potentials were used to calculate Langmuir constants for methane and argon in both structures I and II over a wide range of temperatures and pressures. By incorporating accurate potentials and calculating the full 6-dimensional configurational integral, these Langmuir constants are independent of any fitting parameters. The resulting cell potentials are shown in Figure 2.

The central-well potentials for argon shown in Figure 2 are the simplest cell potentials that will reproduce the calculated Langmuir constants. However, Barrer and Edge ${ }^{59}$ identified that the cell potential for argon exhibits a noncentral minimum for the large cage of the structure I hydrate. Employing the noncentral family of solutions discussed in Section 6.2.3 of Bazant and Trout, ${ }^{1}$ we can reproduce the noncentral minimum; however, for hydrate equilibrium calculations the central-well 


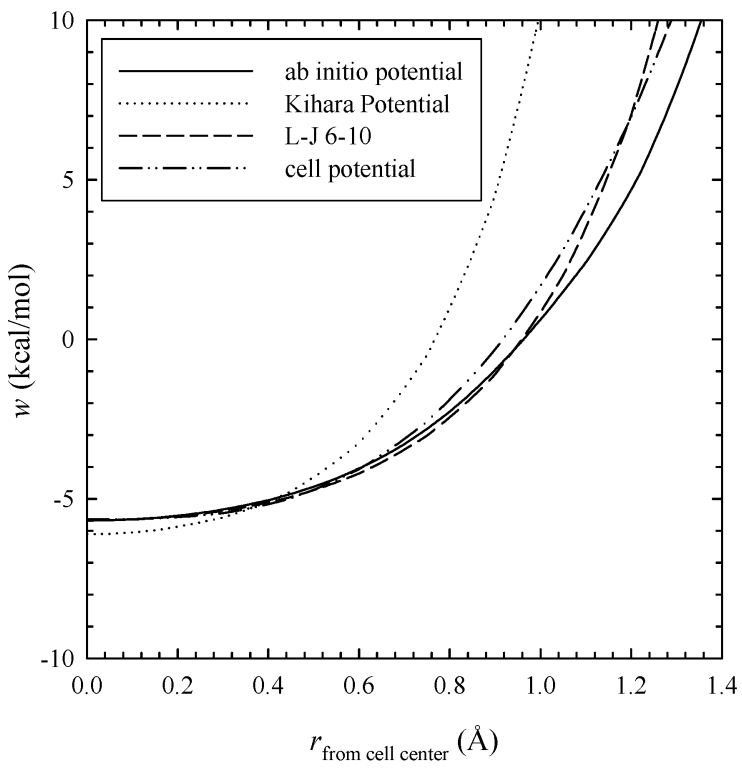

(a)

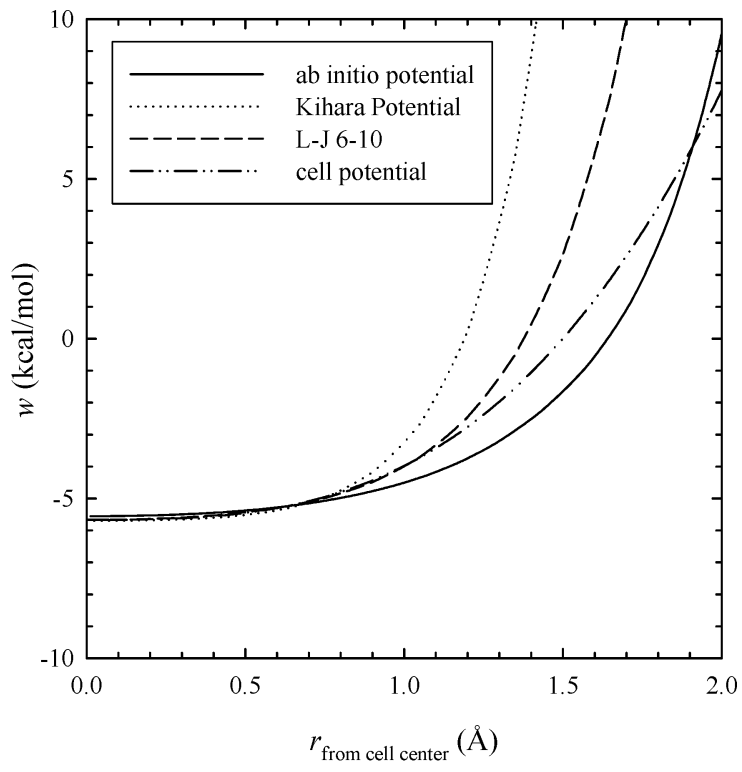

(b)

Figure 3. Fit of common potential forms to spherically averaged ab initio potentials of methane in the small cage (a) and large cage (b) of structure I.

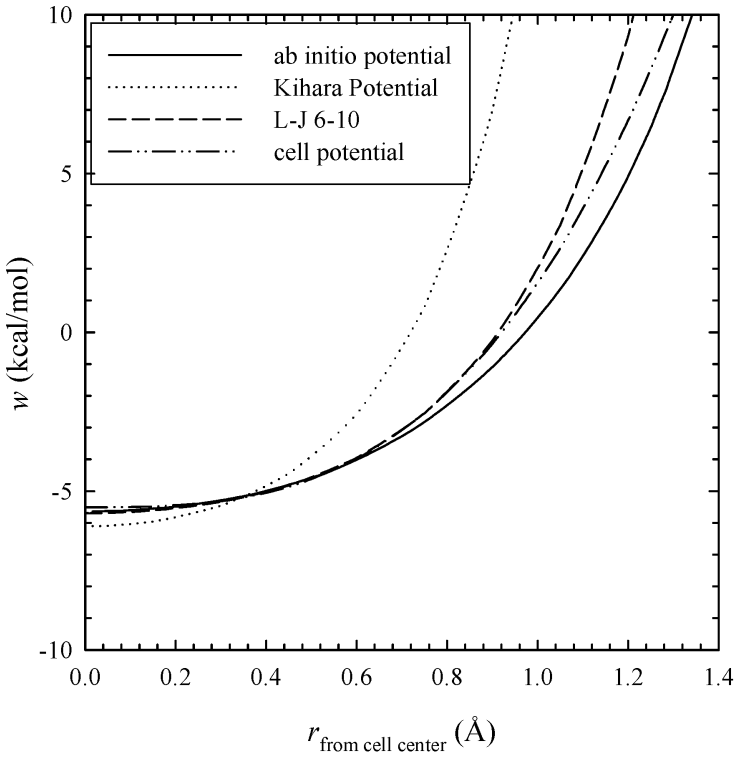

(a)

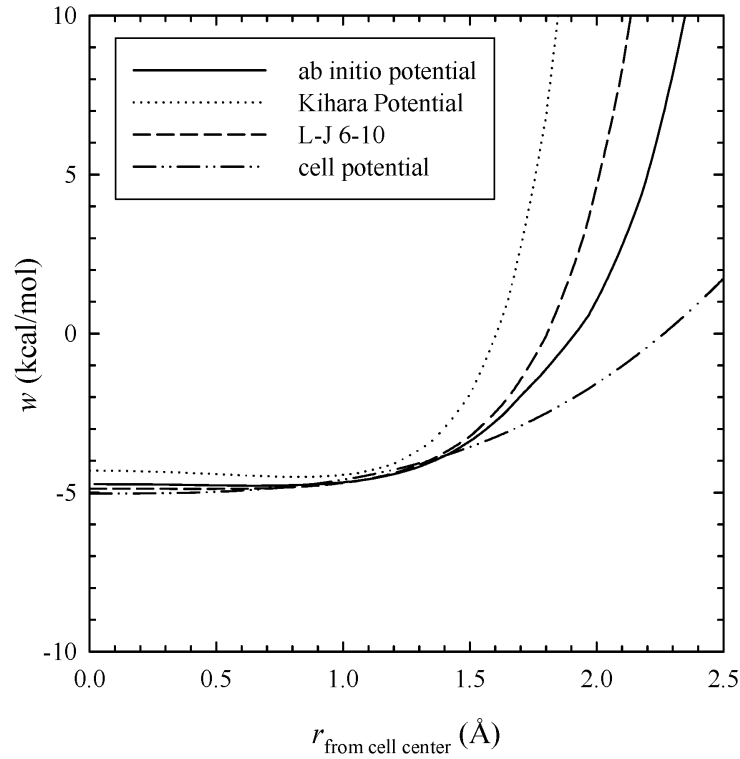

(b)

Figure 4. Fit of common potential forms to spherically averaged ab initio potentials of methane in the small cage (a) and large cage (b) of structure II.

solution accurately reproduces the Langmuir constants and therefore would provide a simpler model with no loss in accuracy.

7.3. Extrapolating Known Cell Potentials from One Structure to Cell Potentials for Other Structures. Following the methodology described in Section 6, various potential forms were fit to the cell potentials previously calculated for methane. Figures 3 and 4 show the Kihara and Lennard-Jones 6-10 potentials fitted to the cell potentials and compared to spherically averaged ab initio structure I cell potentials determined from the full six-dimensional configurational integral, ${ }^{9}$ reproducing the Langmuir constants as shown in Figure 5. It was found that a $\mathrm{L}-\mathrm{J}$ 6-10 potential fit to the structure I cell potentials best reproduces the structure II potentials and the structure I and II Langmuir constants; therefore, a $\mathrm{L}-\mathrm{J}$ 6-10 potential will be used for extrapolation of the ethane structure I cell potentials to find structure II for use in mixture predictions. The best-fit Kihara parameters are $\epsilon / k=147.6 \mathrm{~K}, \sigma=3.17 \AA$, with $a=$ $0.3834 \AA$ while the best fit $\mathrm{L}-\mathrm{J} 6-10$ parameters are $\epsilon / k=$ $192.82 \mathrm{~K}$ and $\sigma=3.441 \AA$.

As evident in Figure 4, the best-fit Kihara potential does not reproduce the attractive volume of the spherically averaged $a b$ initio potential as well as the $\mathrm{L}-\mathrm{J} 6-10$ potential. In fact, this is best illustrated in Figure 5 where the Kihara potential fails to reproduce the Langmuir constants for methane in a structure II lattice. The Kihara potential is inherently too strong in the repulsive region of the methane-water interaction in structure II cavities. It should be noted that all of the spherically averaged pair-type potentials shown in Figure $4 \mathrm{~b}$ ( $\mathrm{ab}$ initio, Kihara, and L-J 6-10) exhibit the noncentral minimum in the large cage of structure II discussed in the previous section. This noncentral behavior is averaged into the cell potential. 

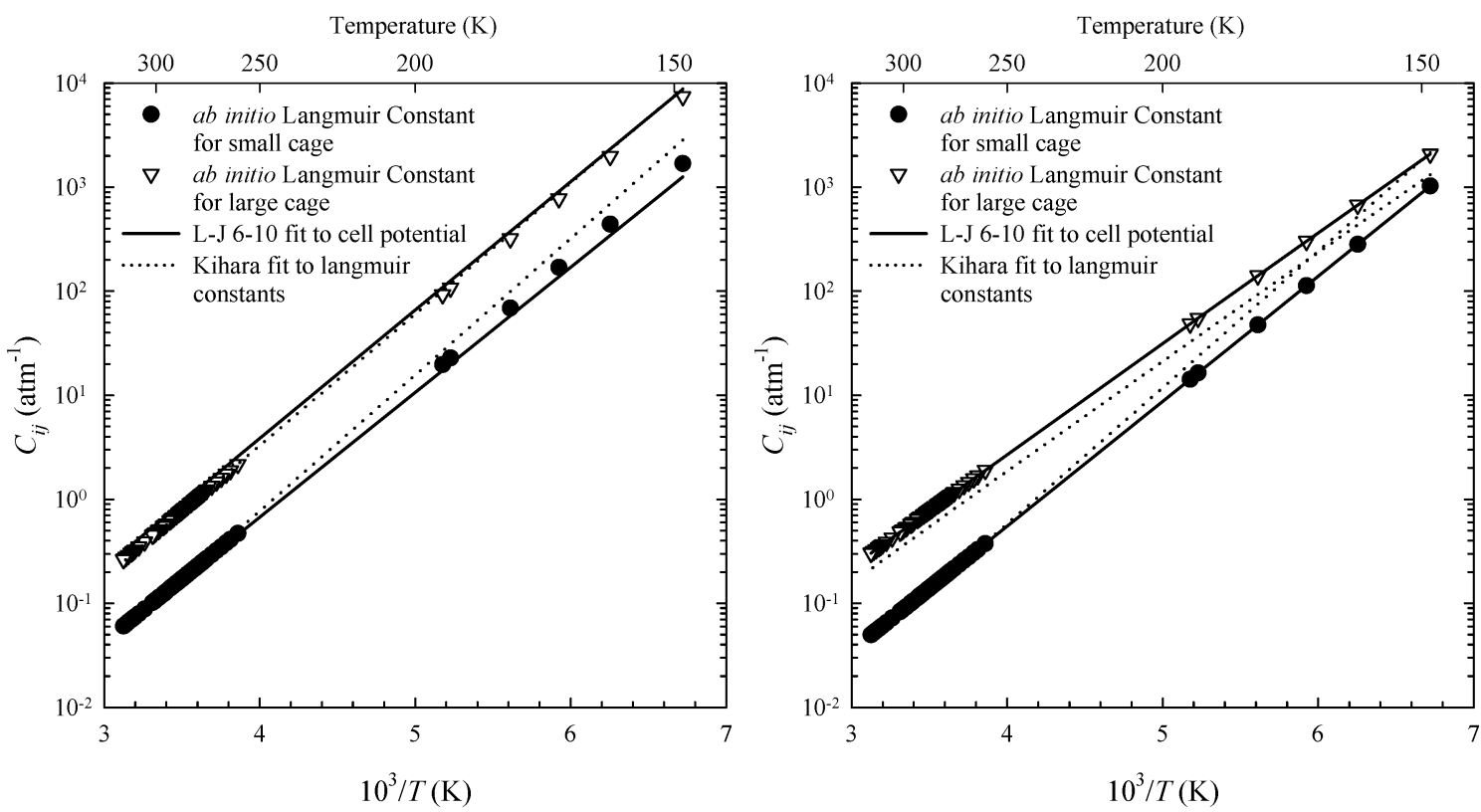

Figure 5. Methane Langmuir constants for structure I (a) and structure II (b) calculated by using fit potential forms compared to values calculated via a site-site ab initio potential. ${ }^{9}$

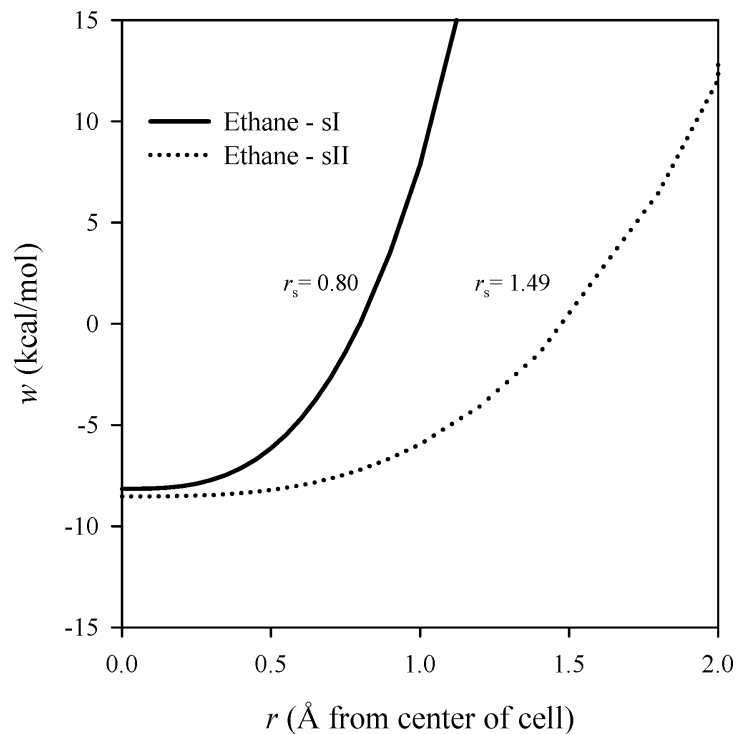

Figure 6. Cell potentials for ethane in the large cage of the structure I and structure II lattice.

After validating the $\mathrm{L}-\mathrm{J} 6-10$ potential form for use in the hydrate lattice, it was used to fit the ethane structure I cell potential and calculate the cell potential for structure II ethane. The fit potential parameters are $\epsilon / k=234.22 \mathrm{~K}$ and $\sigma=3.888$ A. Figure 6 shows the ethane cell potentials for structures I and II.

\section{Phase Equilibrium Predictions}

Because the cell potentials were extracted by using singlecomponent hydrate experimental equilibrium data, the best test of the applicability of the calculated cell potentials with the assumptions inherent in the van der Waals-Platteeuw model and the reference parameters is their ability to predict the phase behavior of mixed gas hydrate systems. Kvamme et al. ${ }^{60}$ showed that guest-guest interactions have a significant effect on Langmuir constants of guest molecules. This energy would be incorporated in the mean field way in the fitting of parameters for pure hydrate systems. For mixed hydrate systems, deviations from this mean field energy could be important over certain composition ranges. Predicting phase equilibria data for mixed hydrate systems provides a test of the generality of the reference parameters used as well as the assumption in the van der Waals-Platteeuw model that the guest-guest interactions can be adequately treated via mean field energies.

In many instances, these predictions can be validated by using existing experimental data, in others, predictions await experimental confirmation. In these predictions the cell potentials were fitted only to the single component hydrate equilibria data and the reference parameters were calculated from methane and argon single component hydrate data. ${ }^{9}$ No parameter fitting to any data from mixed guest hydrate systems was performed.

8.1. Methane Mixtures. Accurate predictions for the mixed methane-ethane hydrate system are of great importance in the production and pipeline transmission of natural gas where hydrate forming temperatures and pressures exist. Figure 7 shows predictions using the methane and ethane cell potentials compared to predictions from the CSMHYD program, ${ }^{6}$ along with experimental data. ${ }^{35,39,61}$ The average absolute deviation (AAD) for the cell potential method is $6.2 \%$ compared to $11.9 \%$ for the CSMHYD. Using the model parameters optimized for the methane-ethane mixture by Ballard and Sloan ${ }^{7}$ the AAD is $10.8 \%$. Similar predictions using the cell potentials in Table 3 for methane-isobutane mixtures result in an AAD of $6.7 \%$ compared to $13.2 \%$ for CSMHYD.

The methane-ethane mixture undergoes a transition from structure I with pure methane to structure II at a methane mole fraction between 0.72 and $0.75^{26,28}$ at $274.2 \mathrm{~K}$, although both guests form structure I as simple hydrates. Using the cell potentials calculated with the pure methane and ethane clathrate data, this method predicts that this structural change will occur at $x_{\mathrm{CH}_{4}}=0.74$, within the range of the experimental measurements. Using the Kihara potential, this transition is predicted to occur at a mole fraction of 0.52 methane. $^{7}$ However, other groups $^{7,29}$ have modified the methane and ethane parameters to reproduce the experimental mole fraction for this transition. Our predicted phase diagram, with no adjustment of parameters, was in agreement with experimental data from Deaton and Frost ${ }^{35}$ and Jhaveri and Robinson ${ }^{62}$ for a methane-ethane-water mixture at $277.6 \mathrm{~K}$ as shown in Figure 8. Our predicted lines 

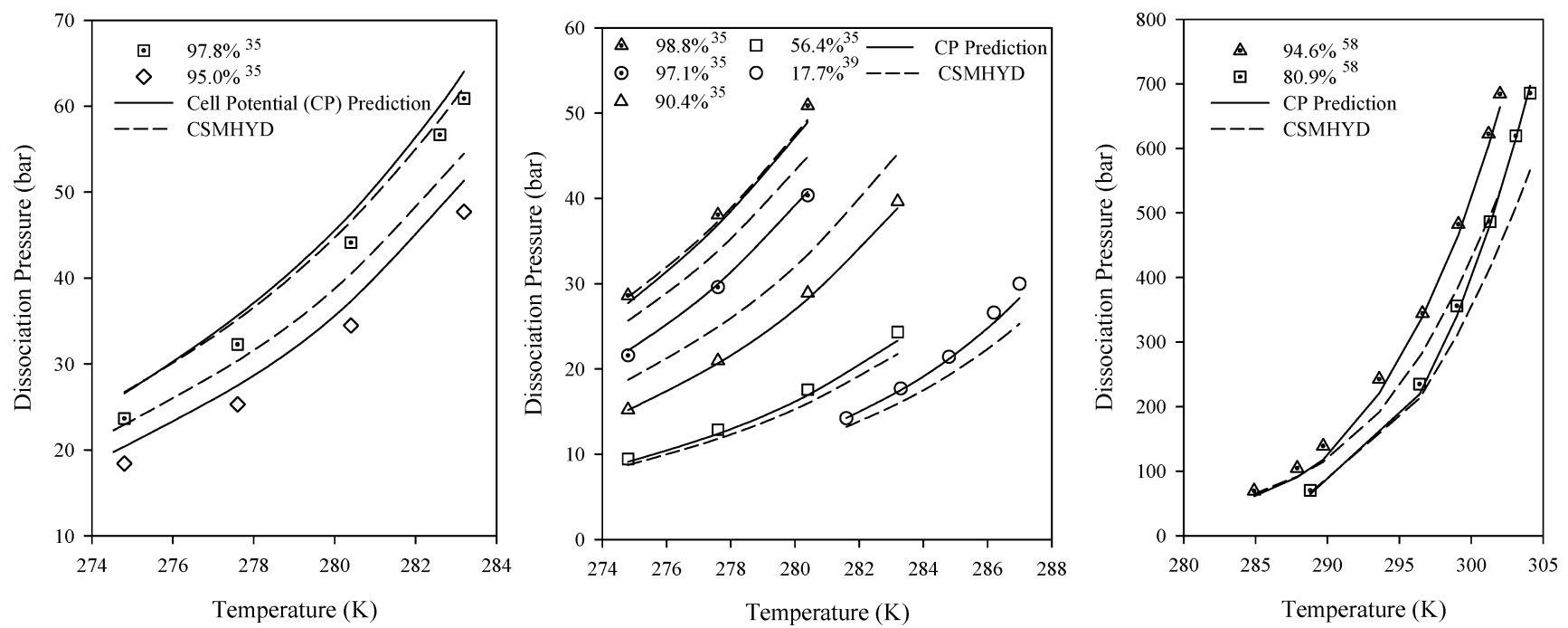

Figure 7. Predicted dissociation pressures for various methane-ethane mixtures compared to experimental data. ${ }^{35,39,61}$

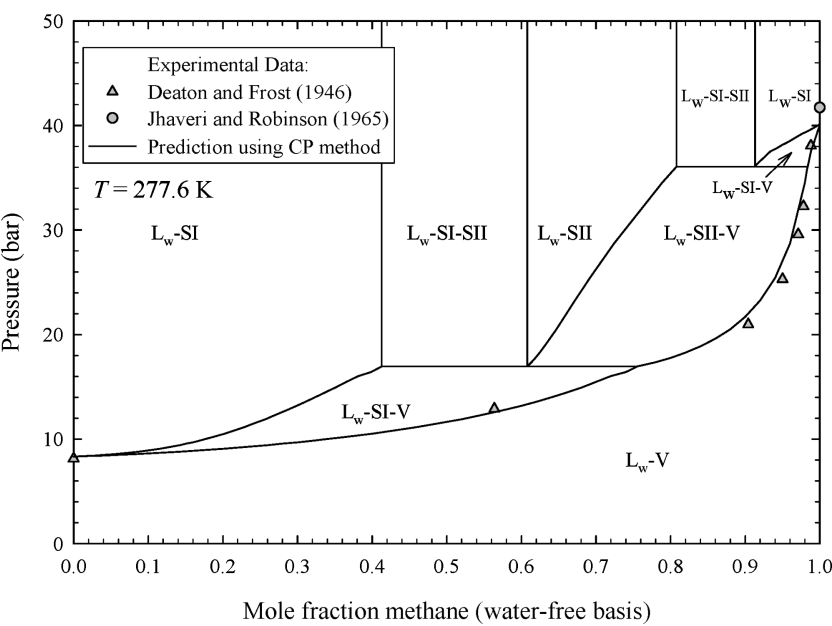

Figure 8. Predicted hydrate phase diagram for methane and ethane at 277.6 K. Experimental data from Deaton and Frost ${ }^{35}$ and Jhaveri and Robinson $^{62}$

directly overlap the measured points within expected experimental uncertainty.

The predicted equilibrium lines shown in Figure 8 and the similar figures that follow were calculated by using the mixture form of the Peng-Robinson equation of state ${ }^{11}$ to calculate the fugacity of the gas and liquid phases of the guests on a waterfree basis. The hydrate-water-guest equilibrium and the composition of the hydrate phase were computed by using the cell potential method. The phases present represent the phases with the lowest free energy. For systems with liquid guest $\left(\mathrm{L}_{\mathrm{hc}}\right)$ hydrate equilibia, the fugacity of the liquid guest mixture is used in the van der Waals-Platteeuw model to calculate the equilibrium pressure. These equilibrium lines are nearly vertical due to the small compressibility of the liquid guest mixture. For the three-component, isothermal systems presented, i.e., water-methane-ethane in Figure 8, a constant pressure lever rule tie line is to be applied whenever there are three phases present at a given composition and pressure. From the Gibbs phase rule, $\mathscr{F}=n+2-\pi-r=2-r$, where $n=$ the number of components $=3, \pi=$ the number of phases $=3, r=$ the number of restrictions or constraints. With $P$ and $T$ specified, $r$ $=2$ and $\mathscr{F}=0$ as expected, so the phase compositions are given by the tie line.

Figure 9 is the pressure vs composition (on a water-free basis) phase diagram for the methane-propane-water system. One

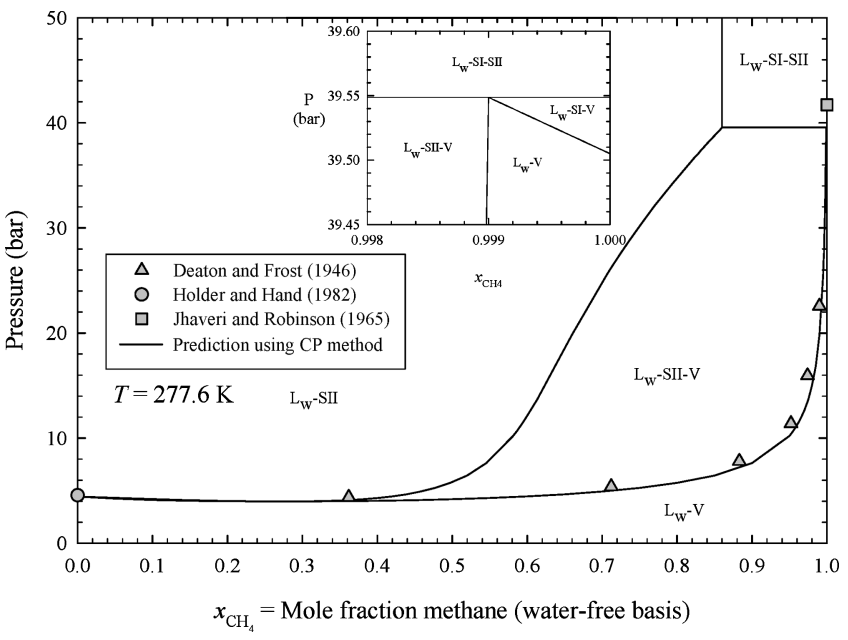

Figure 9. Predicted isothermal hydrate phase diagram for methane and propane at $277.6 \mathrm{~K}$. Experimental data from Deaton and Frost, ${ }^{35}$ Holder and Hand, ${ }^{40}$ and Jhaveri and Robinson. ${ }^{62}$

may notice that at a propane mole fraction composition of 0.001 , a structure II hydrate is predicted to form. This compares to a value of 0.0005 predicted by Ballard and Sloan ${ }^{29}$ by using methane Kihara parameters optimized to the methane-ethane mixture. The structure I to structure II transition point has not been determined experimentally.

Figure 10 is the pressure versus water-free composition isothermal phase diagram for a methane-cyclopropane-water mixture at $277.15 \mathrm{~K}$. Although these $P$ and $T$ conditions are outside the structure II region for pure cyclopropane, as methane is added to pure cyclopropane, we predict that the structure I hydrate changes to a structure II hydrate because methane serves to stabilize the small cage of structure II, while cyclopropane fills the large cage. This structural change is predicted to occur at a methane mole fraction of 0.38 . Because the methane simple hydrate exists as structure I, an upper transition from structure II back to structure I occurs at $0.9996 \mathrm{~mol}$ fraction of methane. Figure 11 is the pressure vs water-free composition phase diagram for a methane-cyclopropane-water mixture at 281.15 K. Similar to the phenomena predicted at $277.15 \mathrm{~K}$, we predict that between 0.566 and $0.9994 \mathrm{~mol}$ fraction of methane the methane-cyclopropane-water system forms a structure II hydrate.

8.2. Other Hydrocarbon Mixtures. Figure 12 shows the results of using the cell potentials for propane and isobutane 


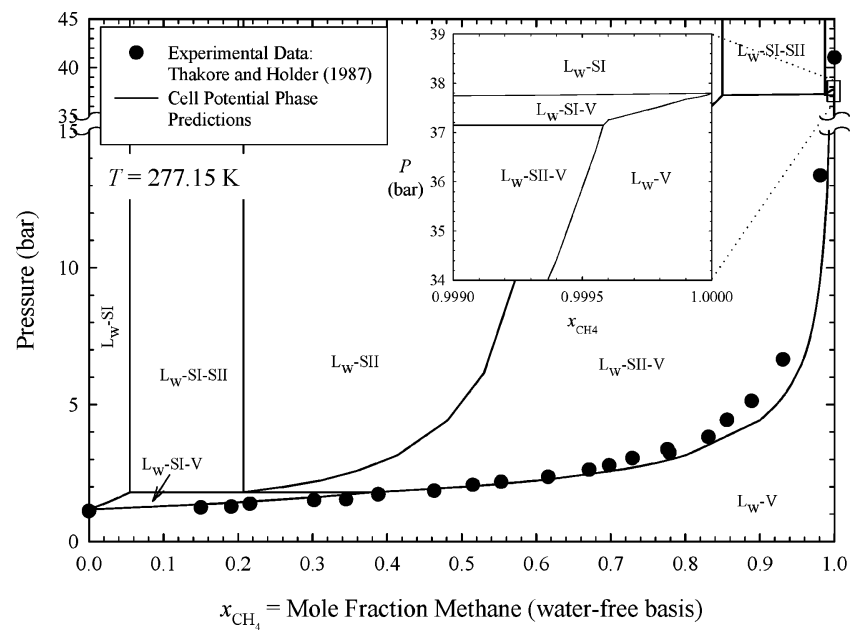

Figure 10. Predicted isothermal hydrate phase diagram for methane and cyclopropane at $277.15 \mathrm{~K}$ compared with experimental data from Thakore and Holder ${ }^{51}$

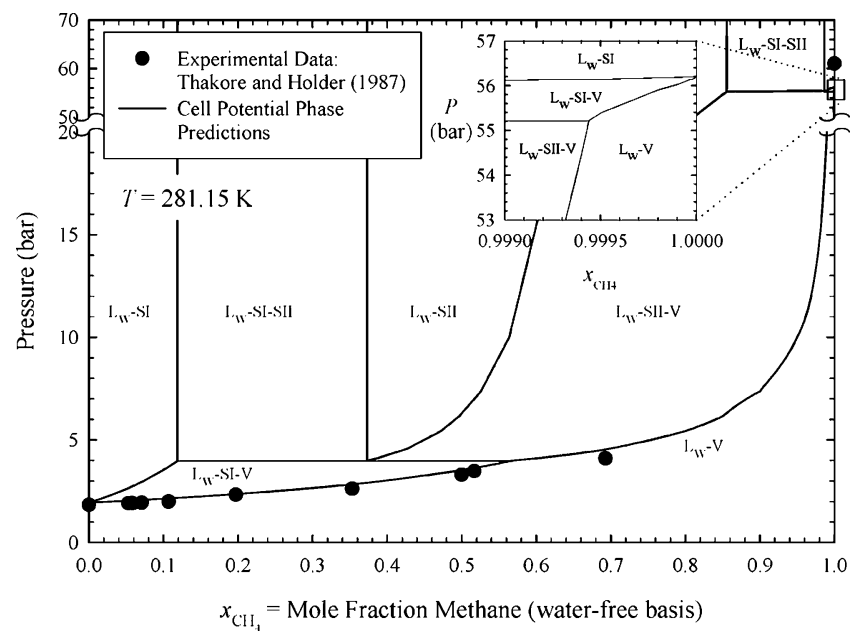

Figure 11. Predicted isothermal hydrate phase diagram for methane and cyclopropane at $281.15 \mathrm{~K}$ compared with experimental data from Thakore and Holder. ${ }^{51}$

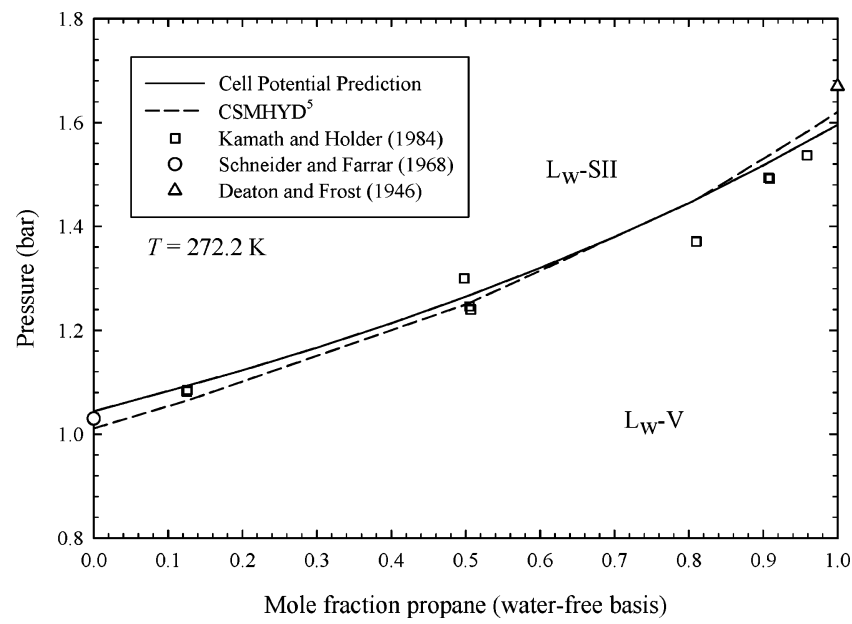

Figure 12. Predicted isothermal hydrate phase equilibrium for propane and isobutane at $272.2 \mathrm{~K}$ with experimental data from Kamath and Holder, ${ }^{65}$ Schneider et al., ${ }^{53}$ and Deaton and Frost. ${ }^{35}$

for the prediction of the hydrate phase equilibrium for the mixture. It is clearly evident that the cell potentials found using only pure component hydrate data are applicable to mixtures. Ballard et al. ${ }^{63}$ show experimental evidence as well as predictions that a methane-propane-water mixture undergoes a

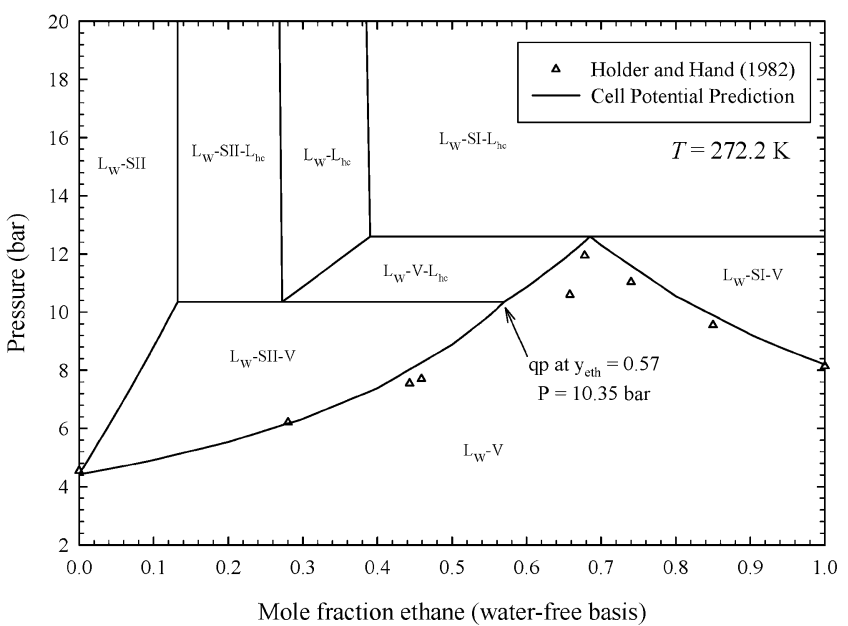

Figure 13. Predicted isothermal hydrate phase diagram for ethane and propane at $277.6 \mathrm{~K}$ with experimental data from Holder and Hand. ${ }^{40}$

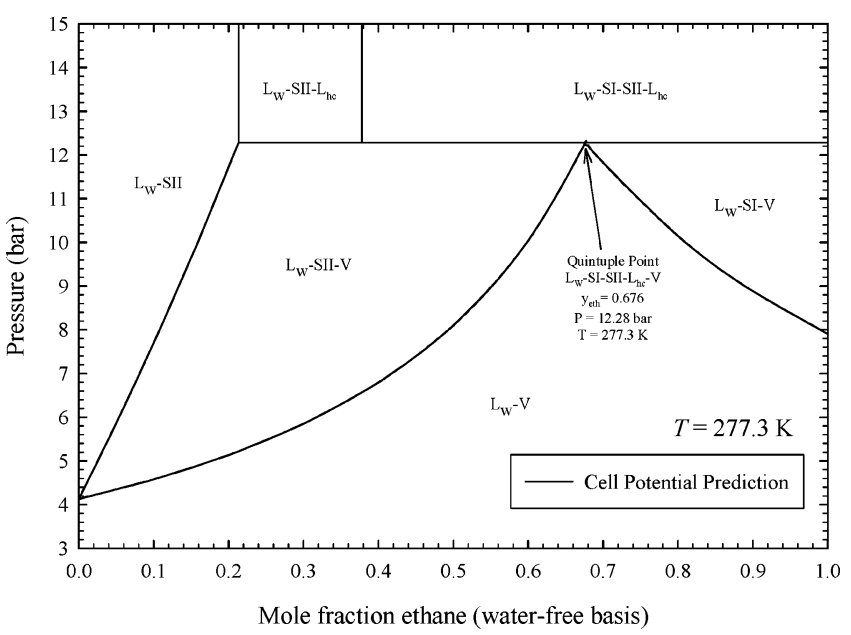

Figure 14. Predicted isothermal hydrate phase diagram for ethane and propane at $277.3 \mathrm{~K}$ with a five-phase quintuple point indicated.

"pseudo-retrograde" decomposition near $278 \mathrm{~K}$. That is, the hydrate will actually decompose upon pressurization. Figure 13 shows the predicted hydrate phase diagram for an ethanepropane-water mixture at $277.6 \mathrm{~K}$. One can see that the cell potentials predict the experimental data of Holder and Hand ${ }^{40}$ well and that we also predict this "pseudo-retrograde" decomposition to occur between 0.60 and $0.685 \mathrm{~mol}$ fraction of ethane. The cell potential method also predicts the 60 known data points for ethane-propane mixtures with an AAD of 5.9\% compared to previous studies by Klauda and Sandler ${ }^{64}(8.86 \%)$ and Sloan ${ }^{6}$ $(10.5 \%)$ and the refit by Ballard and $\operatorname{Sloan}^{29}(5.72 \%)$.

If the mixture presented in Figure 13 is cooled, the $\mathrm{L}_{\mathrm{w}}-\mathrm{V}-$ $\mathrm{L}_{\mathrm{hc}}$ envelope, within which "pseudo-retrograde" decomposition occurs, disappears. The hydrate dissociation pressure decreases at a faster rate than the dew point pressure curve and therefore we predict the "pseudo-retrograde" phenomena to cease at 277.3 $\mathrm{K}$. At this temperature there will be a quintuple point with five phases $\left(\mathrm{L}_{\mathrm{w}}-\mathrm{V}-\mathrm{L}_{\mathrm{hc}}-\mathrm{sII}-\mathrm{sI}\right)$ in equilibrium. For this system, $\mathscr{F}=n+2-\pi=3+2-5=0$. This invariant point is predicted to occur at $T=277.3 \mathrm{~K}, P=12.28$ bar, $y_{\text {eth }}=0.676$ and is shown in Figure 14.

Another mixture that is expected to undergo "pseudoretrograde" decomposition is the ethane-isobutane-water system. ${ }^{63}$ Therefore, it should be expected that a $\mathrm{L}_{\mathrm{w}}-\mathrm{V}-\mathrm{L}_{\mathrm{hc}}-$ sII-sI quintuple point should exist. Figure 15 is the predicted hydrate phase diagram for an ethane-isobutane-water mixture 


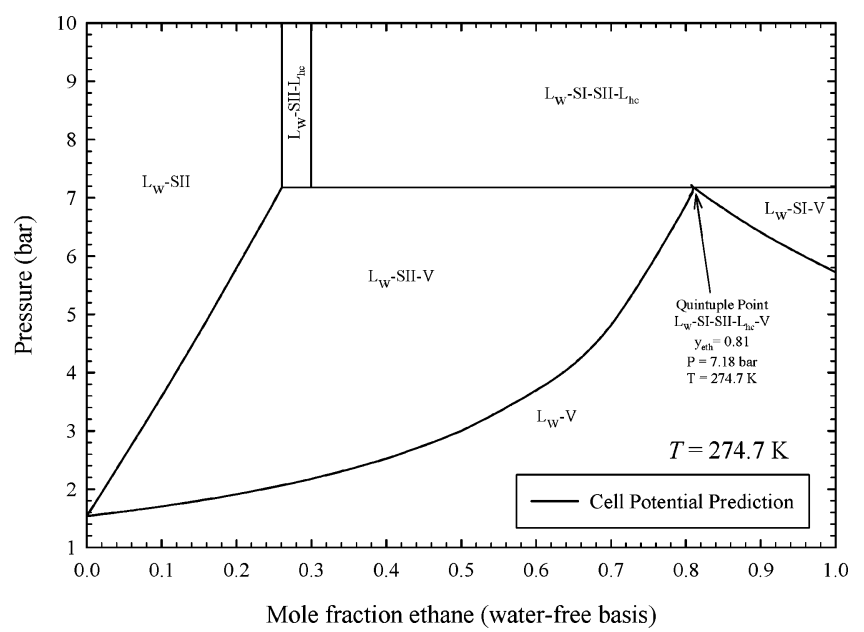

Figure 15. Predicted isothermal hydrate phase diagram for ethane and isobutane at $274.7 \mathrm{~K}$ with a five-phase quintuple point indicated.

at $274.7 \mathrm{~K}$. The quintuple point is predicted to occur at $T=$ $274.7 \mathrm{~K}, P=7.18$ bar, and $y_{\mathrm{eth}}=0.81$.

\section{Conclusions}

We have presented the application of our cell potential method in which the form of the guest-host interaction potential in clathrate hydrates is determined analytically. Our approach was validated by making numerous predictions of multicomponent phase data without fitting mixture data to experiments. The spherically averaged Kihara potential form is adequate in representing the overall guest-host interaction in structure I; however, guest-host interactions in the large cage of structure II are not effectively reproduced, thus leading to inaccurate reference parameters which have commonly appeared in the literature. The reference parameters used in this paper were further validated by their successful utilization in predicting mixed gas hydrate phase equilibrium data. All mixture predictions in this work are performed without fitting to any mixture data and nonetheless predict the experimental data accurately.

Overall, the cell potential method developed in this work has demonstrated its effectiveness and applicability to successfully model mixed hydrate systems without any adjustable parameters. For example, the structure I to structure II transition for methane-ethane gas mixtures was predicted to occur at 0.75 mol fraction of methane at $274.2 \mathrm{~K}$, within the experimental range measured to be $0.72-0.75 \mathrm{~mol}$ fraction of methane. In addition, we were able to extrapolate the results of the calculated cell potentials to other systems. The cell potential that is calculated for ethane in a structure I hydrate lattice provides sufficient quantitative insight into the interaction between ethane and the water surrounding it in the hydrate that we have been able to model the ethane-water interaction in a structure II lattice. Several predictions were also developed that await experimental testing. For example, structure I to structure II phase transitions have been predicted for methane-cyclopropane gas mixtures outside the temperature range of the pure cyclopropane structure II envelope. Quintuple $\left(\mathrm{L}_{\mathrm{w}}-\mathrm{sI}-\mathrm{sII}-\mathrm{L}_{\mathrm{hc}}-\mathrm{V}\right)$ points have been predicted for the ethane-propane-water $\left(277.3 \mathrm{~K}, 12.28 \mathrm{bar}\right.$, and $\left.x_{\text {eth,waterfree }}=0.676\right)$ and ethaneisobutane-water $\left(274.7 \mathrm{~K}, 7.18 \mathrm{bar}\right.$, and $\left.x_{\text {eth,waterfree }}=0.81\right)$ systems.

We conclude by commenting on why it might be that our simple, cubic cell potentials outperform more complicated, fitted potentials when predicting clathrate phase equilibria. In atomistic modeling, potential parameters are usually fit to reproduce the energies of ideal structures, at low (or zero) temperature, which can be calculated by using ab initio methods or taken from experiment. Phase behavior, however, depends on high temperature configurations, which involve complicated deformations of ideal structures. By starting directly from thermodynamic data at finite temperature, and by using a Boltzmann-weighting scheme over a large configuration space when calculating our ab initio potential, ${ }^{9}$ our method easily determines an appropriate cell potential, which accounts for statistical averaging of configurations over a wide range of temperatures. The basic idea of solving an inverse problem for an "exact" thermodynamic potential may find further successful applications in other areas of materials modeling, where ad hoc fitting of ideal structures remains the standard theoretical approach.

Acknowledgment. The authors thank the Singapore-MIT Alliance and the Martin Foundation for its partial support of this research. We also gratefully acknowledge Prof. William Green, Prof. John Deutch, and Dr. Zhitao Cao for their insightful contributions to this work. We also appreciate the help and support provided by the other members of our research groups at MIT and by Dr. Kevin Sparks.

\section{References and Notes} 139.

(1) Bazant, M. Z.; Trout, B. L. Physica A (Amsterdam) 2001, 300,

(2) Davy, H. Phil. Trans. R. Soc. London 1811, 101, 1.

(3) Hammerschmidt, E. G. Ind. Eng. Chem. 1934, 26, 851.

(4) Sloan, E. D. Nature 2003, 426, 353

(5) Kvenvolden, K. A. Rev. Geophys. 1993, 31, 173.

(6) Sloan, E. D., Jr. Clathrate hydrates of natural gases, 2nd ed., revised and expanded; Marcel Dekker: Monticello, NY, 1998.

(7) Ballard, A. L.; Sloan, E. D. Ann. N.Y. Acad. Sci. 2000, 912, 702

(8) Handa, Y. P.; Tse, J. S. J. Phys. Chem. 1986, 90, 5917.

(9) Anderson, B. J.; Tester, J. W.; Trout, B. L. J. Phys. Chem. B 2004, 108,18705

(10) van der Waals, J. H.; Platteeuw, J. C. Adv. Chem. Phys. 1959, 2, 1 . 59.

(12) Sparks, K. A.; Tester, J. W. J. Phys. Chem. 1992, 96, 11022.

(13) Sparks, K. A.; Tester, J. W.; Cao, Z. T.; Trout, B. L. J. Phys. Chem. $B$ 1999, 103, 6300 .

(14) John, V. T.; Papadopoulos, K. D.; Holder, G. D. AIChE J. 1985 , 31,252 .

(15) John, V. T.; Holder, G. D. J. Phys. Chem. 1985, 89, 3279.

(16) Cao, Z. T.; Tester, J. W.; Sparks, K. A.; Trout, B. L. J. Phys. Chem. B 2001, 105, 10950.

(17) Stackelberg, M. v.; Müller, H. R. Z. Elektrochem. 1954, 58, 25.

(18) Holder, G. D.; Corbin, G.; Papadopoulos, K. D. Ind. Eng. Chem. Fund. 1980, 19, 282.

(19) Lennard-Jones, J. E.; Devonshire, A. F. Proc. R. Soc. 1938, 165,

(20) Kihara, T. Rev. Mod. Phys. 1953, 25, 831.

(21) Parrish, W. R.; Prausnitz, J. M. Ind. Eng. Chem. Process Des. Dev. 1972, 11, 26.

(22) Cao, Z.; Tester, J. W.; Trout, B. L. J. Chem. Phys. 2001, 115, 2550

(23) Cao, Z.; Tester, J. W.; Sparks, K. A.; Trout, B. L. J. Phys. Chem. B 2001, 105, 10950.

(24) Cao, Z. T.; Tester, J. W.; Trout, B. L. J. Chem. Phys. 2001, 115 , 2550.

(25) Cao, Z. T.; Tester, J. W.; Trout, B. L. J. Phys. Chem. B 2002, 106, 7681.

(26) Subramanian, S.; Kini, R. A.; Dec, S. F.; Sloan, E. D. Chem. Eng. Sci. 2000, 55, 1981.

(27) Subramanian, S.; Kini, R. A.; Dec, S. F.; Sloan, E. D. Ann. N.Y. Acad. Sci. 2000, 912, 873 .

(28) Subramanian, S.; Ballard, A. L.; Kini, R. A.; Dec, S. F.; Sloan, E. D. Chem. Eng. Sci. 2000, 55, 5763.

(29) Ballard, A. L.; Sloan, E. D. Chem. Eng. Sci. 2001, 56, 6883.

(30) Tester, J. W.; Modell, M. Thermodynamics and its applications, 3rd ed.; Prentice-Hall: Upper Saddle River, NJ, 1997.

(31) Ballard, A. L.; Sloan, E. D. Chem. Eng. Sci. 2000, 55, 5773.

(32) Rodger, P. M. Int. Conf. N. Gas Hydrates 1994, 715, 207.

(33) Tse, J. S. Int. Conf. Natural Gas Hydrates 1994, 715, 187. 

39,37

(35) Deaton, W. M.; Frost, E. M. Gas hydrates and their relation to the operation of natural-gas pipe lines, U.S. Bureau of Mines. Monograph 8, 1946.

(36) Reamer, H. H.; Selleck, F. T.; Sage, B. H. J. Pet. Technol. 1952, 4, 197.

(37) Galloway, T. J.; Ruska, W.; Chappelear, P. S.; Kobayashi, R. Ind. Eng. Chem. Fundam. 1970, 9, 237.

(38) Falabella, B. J.; Vanpee, M. Ind. Eng. Chem. Fundam. 1974, 13, 228.

(39) Holder, G. D.; Grigoriou, G. C. J. Chem. Thermodyn. 1980, 12 1093.

(40) Holder, G. D.; Hand, J. H. AIChE J. 1982, $28,440$.

(41) Ng, H. J.; Robinson, D. B. Fluid Phase Equilib. 1985, 21, 145

(42) Avlonitis, D. Multiphase Equilibria in Oil-Water Hydrate Forming Systems, M.Sc. Thesis, Heriot-Watt University, 1988.

(43) Hafemann, D. R.; Miller, S. L. J. Phys. Chem. 1969, 73, 1392.

(44) Wittstruck, T.; Brey, W., Jr.; Buswell, A. M.; Rodebush, W. H. J. Chem. Eng. Data 1961, 6, 343.

(45) Wilcox, W. I.; Carson, D. B.; Katz, D. L. J. Ind. Eng. Chem. 1941 33,662 . 63.

(46) Miller, B.; Strong, E. R., Jr. Am. Gas Assoc. Monthly 1946, 28,

(47) Robinson, D. B.; Mehta, B. R. J. Can. Pet. Technol. 1971, 10, 33.

(48) Verma, V. K. Gas Hydrates from Liquid Hydrocarbon-Water Systems, Ph.D. Thesis, University of Michigan, 1974.
(49) Holder, G. D.; Godbole, S. P. AIChE J. 1982, 28, 930.

(50) Kubota, H.; Shimizu, K.; Tanaka, Y.; Makita, T. J. Chem. Eng. Jpn. 1984, 17, 423.

(51) Thakore, J. L.; Holder, G. D. Ind. Eng. Chem. Res. 1987, 26, 462.

(52) Patil, S. L. Measurements of Multiphase Gas Hydrates Phase Equilibria: Effect of Inhibitors and Heavier Hydrocarbon Components, M.S. Thesis, University of Alaska, 1987.

(53) Schneider, G. R.; Farar, J.; Hunter, J. A.; Gillam, W. S.; Johnson, S. U.S. Dep. Interior, Office Saline Water Res. Develop. Progr. Rep. 1968 No. 292, 37.

(54) Rouher, O. S.; Barduhn, A. J. Desalination 1969, 6, 57.

(55) Wu, B. J.; Robinson, D. B.; Ng, H. J. J. Chem. Thermodyn. 1976 8,461 .

(56) Dorstewitz, F.; Mewes, D. Chem. Ing. Tech. 1992, 64, 466

(57) Tester, J. W.; Wiegandt, H. F. AIChE J. 1969, 15, 239.

(58) Rodger, P. M. J. Phys. Chem. 1989, 93, 6850.

(59) Barrer, R. M.; Edge, A. V. J. Proc. R. Soc. London 1967, A300, 1.

(60) Kvamme, B.; Lund, A.; Hertzberg, T. Fluid Phase Equilib. 1993 $90,15$.

(61) McLeod, H. O., Jr.; Campbell, J. M. J. Pet. Technol. 1961, 13, 590.

(62) Jhaveri, J.; Robinson, D. B. Can. J. Chem. Eng. 1965, 43, 75.

(63) Ballard, A. L.; Jager, M. D.; Nasrifar, K.; Mooijer-van den Heuvel,

M. M.; Peters, C. J.; Sloan, E. D. Fluid Phase Equilib. 2001, 185, 77.

(64) Klauda, J. B.; Sandler, S. I. Chem. Eng. Sci. 2003, 58, 27.

(65) Holder, G. D.; Kamath, V. A. J. Chem. Thermodyn. 1984, 16, 399. 